\title{
Chemical and Physical Properties of Bone Cement for Vertebroplasty
}

\author{
Po-Liang Lai ${ }^{1}$, Lih-Hui Chen ${ }^{1}$, Wen-Jer Chen ${ }^{1}$, I-Ming Chu ${ }^{2}$
}

\begin{abstract}
Vertebral compression fracture is the most common complication of osteoporosis. It may result in persistent severe pain and limited mobility, and significantly impacts the quality of life. Vertebroplasty involves a percutaneous injection of bone cement into the collapsed vertebrae by fluorescent guide. The most commonly used bone cement in percutaneous vertebroplasty is based on the polymerization of methylmethacrylate monomers to polymethylmethacrylate (PMMA) polymers. However, information on the properties of bone cement is mostly published in the biomaterial sciences literature, a source with which the clinical community is generally unfamiliar. This review focuses on the chemistry of bone cement polymerization and the physical properties of PMMA. The effects of altering the portions and contents of monomer liquid and polymer powders on the setting time, polymerization temperature, and compressive strength of the cement are also discussed. This information will allow spine

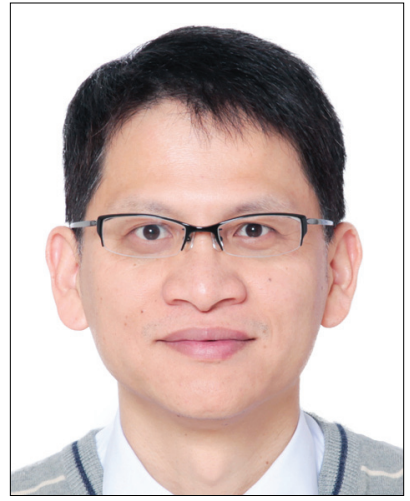

Dr. Po-Liang Lai surgeons to manipulate bone cement characteristics for specific clinical applications and improve safety. (Biomed J 2013;36:162-167)
\end{abstract}

Key words: bone cement, compression fracture, osteoporosis, vertebroplasty

$\mathrm{P}$ ercutaneous vertebroplasty has been widely accepted for the treatment of osteoporotic vertebral compression fracture. However, the chemical and physical properties of bone cement are not easily accessible to spine surgeon because they are discussed mainly in the engineering and biomaterial literatures. Therefore, the authors reviewed the basic properties of bone cement with a view toward percutaneous vertebroplasty. This article will focus on the chemical and physical properties of bone cement polymerization. Then we will discuss how to alter the setting time, exothermic reaction, and mechanical strength by controlling the polymerization temperature, monomer-to-polymer ratio, and mixing method. We hope that the basic principles of polymerization chemistry will strengthen the confidence with which spine surgeons consider different products and encourage studies aimed at developing new materials and devices to improve cement delivery.

\section{Vertebral compression fracture}

Osteoporotic vertebral fractures are a major senile health problem that causes severe, debilitating back pain with consequently reduced daily activity. Conservative management, including analgesics, bed rest, braces, and rehabilitation, is indicated in patients who do not have neurologic impairment. ${ }^{[1]}$ Surgical treatment is indicated for patients who are refractory to conservative treatment, associated with spinal instability or neurologic deficit. ${ }^{[2]}$ Magnetic Resonance Imaging (MRI) is the standard for differentiating between benign compression and malignant pathologic fractures. Besides, MRI can detect some occult vertebral fractures that are not shown in X-ray.

\section{Vertebroplasty}

Vertebroplasty has been widely accepted as a therapeutic strategy for painful osteoporotic compression fractures. ${ }^{[3-6]}$ In this procedure, bone cement is percutaneously injected under pressure into a vertebra through a cannula [Figure 1]. Polymerization of the bone cement stabilizes the fractured vertebra by increasing its mechanical strength, thereby provid-

From the ${ }^{1}$ Department of Orthopaedic Surgery, Chang Gung Memorial Hospital at Linkou, Chang Gung University College of Medicine, Taoyuan, Taiwan; ${ }^{2}$ Department of Chemical Engineering, National Tsing Hua University, Hsinchu, Taiwan

Received: May 22, 2012; Accepted: Mar. 12, 2013

Correspondence to: Dr. Po-Liang Lai, Department of Orthopaedic Surgery, Chang Gung Memorial Hospital at Linkou. 5, Fusing St., Gueishan, Taoyuan 333, Taiwan (R.O.C.). Tel: 886-3-3281200; ext. 3612; Fax: 886-3-3278113; E-mail: polianglai@gmail.com

DOI: $10.4103 / 2319-4170.112750$ 
ing symptomatic pain relief. ${ }^{[3,7,8]}$ Vertebroplasty is a very good surgical choice, as this surgical procedure eliminates the risk of major spinal surgery, and through rapid pain relief, may provide early ambulation and rehabilitation for elderly patients. ${ }^{[9,10]}$

A report on vertebroplasty was first published in 1987 for the management of a painful, aggressive hemangioma of a vertebral body. ${ }^{[11]}$ Some surgeons extend its application to refractory pain due to spinal myeloma or metastases. However, cortical destruction, presence of an epidural soft-tissue mass, highly vascularized lesions, and severe vertebral collapses are the factors that increase the rate of complications. ${ }^{[12]}$ The main indications for vertebroplasty are (1) intractable, intense pain due to the fracture of osteoporotic fractures diagnosed by radiographs, computed tomography (CT), or MRI and (2) refractory to conservative management for at least 3-4 weeks.

\section{Polymethylmethacrylate}

Polymethylmethacrylate (PMMA) is a type of bone cement frequently used for clinical applications in orthope-

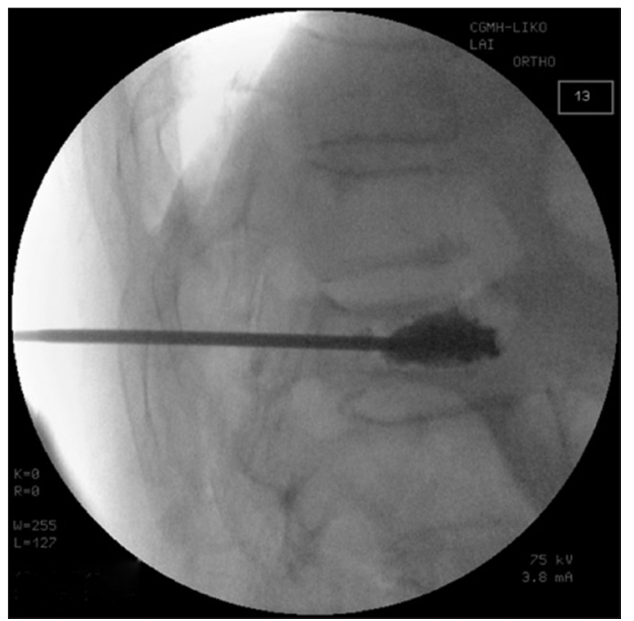

Figure 1: The fluorescence image shows the bone cement is injected into the fractured vertebra through a cannula. dic surgery. From a chemical point of view, methylmethacrylate (MMA) is an ester of methacrylic acid with a polymerizable double bond. Functions of bone cements include fixation of prostheses, anchoring of implant to the bone, and as drug carriers for antibiotics. PMMA cures rapidly and offers mechanical stability within a few minutes. The filling materials used for vertebroplasty require good biocompatibility, good biomechanical strength and stiffness, and good radio-opacity for the fluoroscopy-guided procedures. The effective improvement of pain with vertebroplasty is attributed to increased mechanical strength of vertebral bodies after bone cement infusion. ${ }^{[13]}$ Besides, exothermic reaction of cement polymerization is hypothesized to block sensory nerve. ${ }^{[14]}$

\section{Polymerization reaction}

Polymers are large molecules composed of individual repeating units (monomers). Bone cements are usually supplied as two-component systems that are made of liquid and powder. The powder mainly consists of bead-shaped particles of typically $40 \mu \mathrm{m}$ in diameter. These particles contain, in addition to MMA copolymers, benzoyl peroxide (BPO; the so-called initiator) and zirconium or barium to provide radio-opacity. ${ }^{[15]}$ The second component, the liquid, mainly contains the monomers. Polymerization begins by the addition mechanism in which a monomer becomes unstable by reacting with an initiator. When the two components are mixed, polymerization is initiated and self-curing occurs. At room temperature, monomer polymerization is activated in the presence of free radicals. ${ }^{[16]}$ These radicals are produced during the reaction of the initiator BPO contained in the powder [Figure 2]. A smaller portion of the residual monomer is released and metabolized to carbon dioxide and water in the citric acid cycle. ${ }^{[17]}$

Cement is made radio-opaque by adding barium sulfate or zirconium dioxide compounds to the powder. Although commercial kits often contain small amounts of radiopacifi-

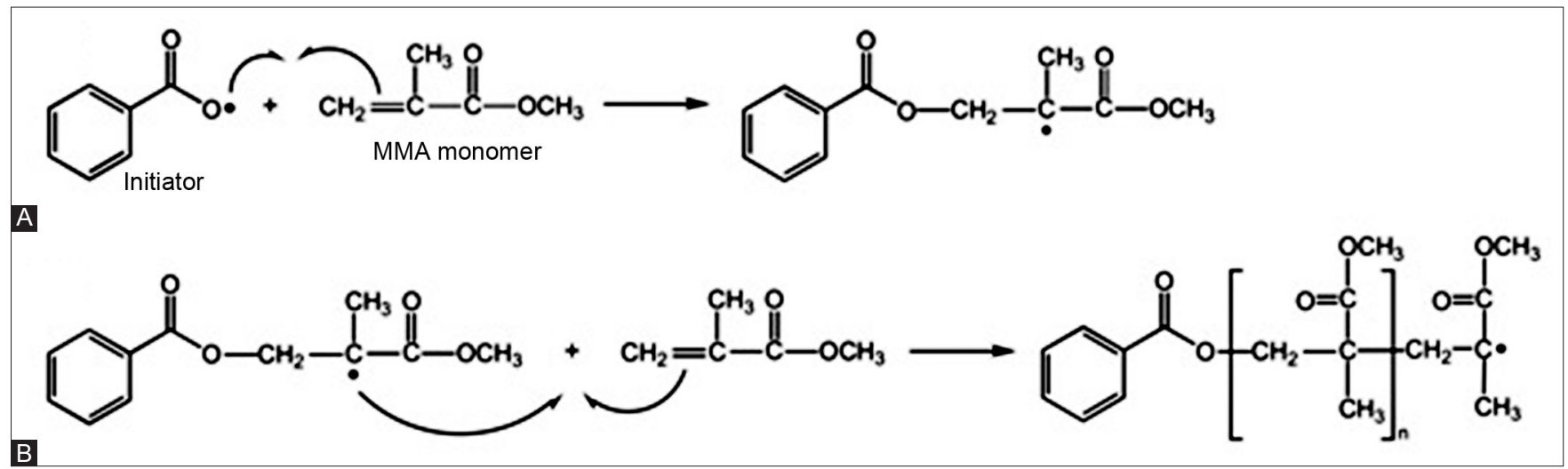

Figure 2: (A) Benzoyl peroxide initiates the methacrylate (MMA) monomer to form a radical that can attack the double bound of another MMA monomer. (B) Polymerization begins by the addition mechanism. 
ers, interventional procedures such as vertebroplasty relying on fluoroscopic monitoring require additional radiopacifiers for better visualization. ${ }^{[18]}$ Clinicians can enhance the structural integrity of radiopacified cement in a number of ways. First, there are indications that zirconium is superior to barium structurally and may be the agent of choice. ${ }^{[19]}$ Second, homogeneity of mixed cement is key; failure to disperse barium particles evenly leads to fracture formation. Third, new cross-linking agents and preparation methods that enhance cement strength have been reported. ${ }^{[19,20]}$ Incorporating these concepts into cement formulations will minimize any loss of strength or durability from radiopacifiers. Compared with bone cements with barium sulfate, bone cements with zirconium dioxide have a significantly higher opacity.

The bone cement begins curing at a rapid rate immediately after the liquid monomers and powder polymers are mixed. ${ }^{[21]}$ Due to the fast polymerization rate, an exponential increase in cement viscosity occurs. The average polymerization time is around 2-5 min, depending on the temperature and the manufacturer. The operator has a limited time available to deliver the bone cement through the spinal cannula into the body. The short handling time leads to an increased probability that a surgeon might miss the crucial time frame in which the cement has the ideal viscosity for a successful injection. ${ }^{[22]}$ Once polymerization ends, the temperature decreases and the cement becomes solid.

\section{Phase of polymerization}

First, the polymer powder adsorbs the monomer liquid, forming a more or less viscous fluid or dough. The reasons for this behavior are the swelling and dissolution processes of monomer and polymer powder. Second, a chemical process is initiated, which is responsible for the final hardening of the bone cement. The handling of bone cement can be described by four different phases, based on the viscosities. ${ }^{[16]}$ They are as follows. (1) The mixing phase (up to $1 \mathrm{~min}$ ) is the period required to thoroughly homogenize the powder and the liquid. The powder and the liquid can be mixed manually by using a bowl and a spatula. (2) The liquid phase (up to several minutes, according to the type of cement and the handling temperature) is the period required to reach a non-sticky state of the cement. (3) The working phase (2-4 min, according to the type of cement and the handling temperature) is the period in which the cement is injected. (4) The hardening phase is a short period during the final setting process and the development of polymerization heat.

An early injection in the liquid phase may result in bone cement extravasation into the venous system, as well as its distant migration to the lungs. ${ }^{[23,24]}$ If paravertebral vein filling is observed by fluoroscopy, cement injection should be stopped and staged. Cement viscosity also has to be sufficiently high to withstand the blood pressure. Blood pervasion of the cement is followed by a reduction in its strength. On the contrary, a late injection at too high a viscosity may result in poor interfaces between the cement and the bone. Besides, it is difficult to inject the cement through the cannula or spinal needles when it is approaching the final hardening stage. The viscosity is the most important handling property for the surgeon and determines the working properties of the cement. The timing for the injection of the cement is important to the success of the surgery. ${ }^{[25]}$

\section{Exothermic reaction}

Cement polymerization is an exothermic reaction. ${ }^{[4,26]}$ There is heat formation of $57 \mathrm{~kJ}$ per mole MMA (molar mass of MMA $=100 \mathrm{~g}$ ) resulting in a temperature increase in the curing bone cement. ${ }^{[16]}$ The Arrhenius equation illustrates the exponential effect of temperature on the reaction. ${ }^{[27]}$ In short, the Arrhenius equation gives the dependence of the rate constant $k$ of chemical reactions on the temperature $T$ (in absolute temperature or kelvins) and activation energy Ea as shown below:

$$
k=\mathrm{A}^{*} \exp (\mathrm{Ea} / \mathrm{R} T)
$$

By lowering the temperature $T$, a decreased rate constant $k$ can be expected. This means that lowering the handling temperature can extend polymerization time. The instructive package inserts of commercially available products provide graphic information on the duration of each period related to temperature. Core temperatures of $77.3^{\circ} \mathrm{C}$ have been measured in the center of bone cement for vertebroplasty in an in vitro study. This is beyond the coagulation temperature of proteins. The in vivo temperature may be lower. The reasons for the lower temperature in vivo are blood circulation, and heat dissipation to the peripheral tissue. $^{[16]}$

According to the Arrhenius equation, cooling the mixture is an important contributor to decrease the reaction rate of polymerization and results in increasing the duration of injectability. Cooling the bone cement can be achieved by storing the liquid and powder in the refrigerator overnight before mixing or by immerging the mixture in the ice water before injection. It has been recognized that temperature reduction has a significant influence on the cement polymerization time. ${ }^{[26,28-30]}$ The liquid time and paste time increased dramatically. The procedure can be performed in a controlled manner without time pressure and, theoretically, it will reduce the possibility of cement leakage. ${ }^{[28,30]}$ Some clinicians routinely used temperature reduction methods in percutaneous vertebroplasty and found no adverse side effects. ${ }^{[21,30]}$ The increased handling time allows the clinician to leave the cement, which has filled the leak side or the paravertebral vein, to act as a plug before continuing its 
injection. The increased handling time also provides more time, after cement mixing, to check the filling of bone cement within the vertebral body. The method is also a good tool to provide training opportunities. Multiple injections from one preparation in different vertebrae become possible, especially by using the ice bath technique.

\section{Physical properties}

Because cement curing is a polymerization process, there is volume shrinkage during curing of the bone cement. The reason for this shrinkage is the decreasing molecular distance between free monomer molecules before the polymerization and the molecular distance of the molecules bonded in the polymer chain. The theoretic volume shrinkage of bone cements is, therefore, approximately 6\%-7\%. The real shrinkage is lower, however, because of the air inclusions in the cement dough. ${ }^{[16]}$ Porosity created by air inclusion results in weakness of bone cement. Centrifugation may be an effective method for limiting porosity. Bone cement manufactured by centrifuging the powder/monomer mixture had increased fatigue life with greater consistency among different samples than the bone cement created using the bow and spatula mixing technique. ${ }^{[31]}$

Cement augmentation appeared to strengthen vertebrae against stress loading. The magnitude of strength increase from vertebroplasty was variable and did not correlate with the volume of cement injected. ${ }^{[32]} \mathrm{A}$ biomechanical study shows that about $3.5 \mathrm{ml}$ of PMMA largely restored normal stress distributions to fractured and adjacent vertebral bodies, but $7 \mathrm{ml}$ was required to restore motion segment stiffness and load sharing between the vertebral bodies and neural arch. ${ }^{[33]}$

To enhance visualization of cement flow during injection and to monitor and prevent leakage beyond the confines of the vertebral body, surgeons have increased the amount of radiopacifiers in the bone cement. Barium sulfate and zirconium dioxide are the two most common radiopacifiers used in contemporary bone cements. Agglomerates of barium sulfate or zirconium dioxide radiopacifier particles may initiate fatigue cracks and adversely affect the fatigue life of the cement. ${ }^{[34]}$ In a study of static and mechanical behavior of bone cement with elevated barium sulfate content, the mechanical strength dose not obviously decrease with $10 \%$ of the powder formulation on a weight basis. However, agglomerations of barium sulfate acted as local stress concentrations and were responsible for the lower tensile and fatigue properties when barium sulfate was $30 \%$. Generally, radiopacifiers are $10 \%-15 \%$ of the powder formulation on a weight basis. ${ }^{[35]}$

Three categories of factors influencing cement flow in the vertebral body can be identified: (1) bone and fracture-related parameters, (2) cement properties, and (3) injection methods. ${ }^{[24]}$ Because PMMA is a two-component mixture that undergoes an exponential curing phase before solidifying, its viscosity is not constant and the cement transforms from a liquid to a solid state. Therefore, the time interval between mixing of the components until the beginning of injection influences the material's viscosity. Cement viscosity was calculated by the Hagen-Poiseuille law given below:

$$
\eta=(P D / 4 L) /\left(32 Q / \pi D^{3}\right)
$$

It expresses viscosity as a function of cannula geometry (inner diameter $D$ and length $L$ ), volumetric flow rate $Q$, and injection pressure $P{ }^{[32,36]}$ The starting viscosity increase from 50 to $100 \mathrm{~Pa} \cdot \mathrm{s}$ resulted in significantly denser and more circular cement patterns in the human specimen as well. ${ }^{[24]}$

\section{Alternative materials}

New filler materials, such as composite resin materials, calcium phosphate, or calcium sulfate cements, in addition to new PMMA formulations are now available for clinical use. ${ }^{[14]}$ For both short and intermediate time periods, the injection of absorbable $\mathrm{CaP}$ cement has shown to be an effective method to treat large vertebral defects. ${ }^{\left[{ }^{[7]}\right.}$ Early results indicate that $\mathrm{CaP}$ remodeling might result in the resorption of the majority of the cement with replacement by lamellar bone. However, some advocate the risk of early collapse after injection of absorbable cement. Lewis et al. reported that bioactive glass is compatible with PMMA bone cement in terms of axial compressive strength. ${ }^{[38]}$ Further studies are needed to evaluate those new materials for augmenting fractured vertebrae.

In order to decrease the possibility of thermal injury and cement leakage, new bone cements with properties of lower temperature, longer handling time, and higher viscosity have been developed. In a study comparing standard and low-temperature medium-viscosity PMMA, there was no difference in the volume of injection, degree of inter-digitation, proportion of bipedicular procedures, incidence of new vertebral fractures, complications, and satisfactory rates. ${ }^{[39]}$ Viscosity of PMMA bone cement, however, was identified as an independent predictor of cement extravasation.

\section{Clinical complications}

Most problems are caused by the extravasation of bone cement into the spinal canal and venous system. The possible leakage sides include paravertebral soft tissue, intervertebral disc, needle tract, epidural and vertebral veins, spinal canal, and neural foramen. Several studies reported complications caused by cement leakage, with subsequent neurologic sequels..$^{[3,23,40]}$ The space-occupying bone cement may cause mechanical compression to the neural tissue and lead to subsequent neurologic deficit. The 
incidence of cement extravasation is up to $40 \%$; however, significant adverse clinical events occur in only less than $1 \%$ of the patients. ${ }^{[41]}$ Cement leakage into the paravertebral venous system may result in embolization of its particles into the right cardiac chambers and pulmonary artery. ${ }^{[12,42]}$ The literature research revealed that the risk of a pulmonary embolism ranges from $3.5 \%$ to $23 \%$ for osteoporotic fractures. ${ }^{[43]}$

Thermal damage to intraosseous neural tissue caused by cement polymerization cannot be ruled out as a potential mechanism for pain relief experienced by patients subsequent to vertebroplasty. ${ }^{[4]}$ In addition, exothermic reaction of the bone cement may cause thermal damage to surrounding tissue ${ }^{[21]}$ Combination of mechanical compression and thermal damage of cement leakage may cause further neurologic deficit beyond the findings of image studies.

Rigid cement augmentation may facilitate the subsequent collapse of the adjacent vertebrae. Cranial vertebrae were most likely to fracture at the adjacent level. New fractures occurred in $18.9 \%$ of 106 patients at 22 adjacent vertebral bodies after percutaneous vertebroplasty during at least 24 months of follow-up. ${ }^{[44]}$ Thoracolumbar junction is a risk factor for new fractures. ${ }^{[45]}$ Chen $e t$ al. reported that larger height restoration and solid lump filling cement are the risk factors of cemented vertebral body. Symmetric cement distribution and fluid aspiration would be the potential ways to avoid fracture of cemented vertebral bodies. ${ }^{[18]}$

\section{Conclusions}

All bone cements on the market fulfill the basic requirements for an orthopedic implant, but there are differences in their properties because of the different powder and liquid compositions. Not all bone cements are alike, and therefore, it is the surgeon's own choice to use an appropriate material to get the optimal result for the patient. Modifying the cement characteristics is the key to improving patient health. Research needs to be done to determine which material properties are clinically relevant for vertebroplasty. Polymerization or the curing interval can be manipulated by changing the handling temperature. The clinicians can take advantage of the increased working time and the improved injectability without increased costs by cooling the bone cements.

Vertebroplasty can improve the quality of life and physical activity of patients with painful vertebral compression fracture. Most of the pain can be relieved significantly, which reduces the demand for analgesics. Mechanical stabilization of fractured vertebra and thermal necrosis of nerve endings are the main reasons of postoperative pain relief. Even though vertebroplasty has a low incidence of complications, some potentially serious sequelae should be discussed with the patients and their family before surgery.

\section{REFERENCES}

1. Denaro L, Longo UG, Denaro V. Vertebroplasty and kyphoplasty: Reasons for concern? Orthop Clin North Am 2009;40:465-71.

2. Dickman CA, Fessler RG, MacMillan M, Haid RW. Transpedicular screw-rod fixation of the lumbar spine: Operative technique and outcome in 104 cases. J Neurosurg 1992;77:860-70.

3. McArthur N, Kasperk C, Baier M, Tanner M, Gritzbach B, Schoierer O, et al. 1150 kyphoplasties over 7 years: Indications, techniques, and intraoperative complications. Orthopedics 2009;32:90.

4. Deramond H, Wright N, Belkoff S. Temperature elevation caused by bone cement polymerization during vertebroplasty. Bone 1999;25 (2 Suppl):17-21S

5. Anselmetti GC, Zoarski G, Manca A, Masala S, Eminefendic H, Russo F, et al. Percutaneous vertebroplasty and bone cement leakage: Clinical experience with a new high-viscosity bone cement and delivery system for vertebral augmentation in benign and malignant compression fractures. Cardiovasc Intervent Radiol 2008;31:937-47.

6. Lee MJ, Dumonski M, Cahill P, Stanley T, Park D, Singh K. Percutaneous treatment of vertebral compression fractures: A meta-analysis of complications. Spine 2009;34:1228-32.

7. Masala S, Mastrangeli R, Petrella MC, Massari F, Ursone A, Simonetti G. Percutaneous vertebroplasty in 1,253 levels: Results and long-term effectiveness in a single centre. Eur Radiol 2009; $19: 165-71$

8. Weisskopf M, Weikopf M, Ohnsorge JA, Niethard FU. Intravertebral pressure during vertebroplasty and balloon kyphoplasty: An in vitro study. Spine 2008;33:178-82.

9. Chen JF, Lee ST, Lui TN, Wu CT, Liao CC. Percutaneous vertebroplasty for the treatment of osteoporotic vertebral compression fractures: A preliminary report. Chang Gung Med J 2002;25:306-14

10. Chen LH, Niu CC, Yu SW, Fu TS, Lai PL, Chen WJ. Minimally invasive treatment of osteoporotic vertebral compression fracture. Chang Gung Med J 2004;27:261-7.

11. Galibert P, Deramond H, Rosat P, Le Gars D. Preliminary note on the treatment of vertebral angioma by percutaneous acrylic vertebroplasty. Neurochirurgie 1987;33:166-8.

12. Laredo JD, Hamze B. Complications of percutaneous vertebroplasty and their prevention. Skeletal Radiol 2004;33:493-505.

13. Deramond H, Depriester C, Galibert P, Le Gars D. Percutaneous vertebroplasty with polymethylmethacrylate. Technique, indications, and results. Radiol Clin North Am 1998;36:533-46.

14. Lieberman IH, Togawa D, Kayanja MM. Vertebroplasty and kyphoplasty: Filler materials. Spine J 2005;5 (6 Suppl):305-16S.

15. Nussbaum DA, Gailloud P, Murphy K. The chemistry of acrylic bone cements and implications for clinical use in image-guided therapy. J Vasc Interv Radiol 2004;15:121-6.

16. Kuehn K-D, Ege W, Gopp U. Acrylic bone cements: Composition and properties. Orthop Clin North Am 2005;36:17-28.

17. Wenda K, Scheuermann H, Weitzel E, Rudigier J. Pharmacokinetics of methylmethacrylate monomer during total hip replacement in man. Arch Orthop Trauma Surg 1988;107:316-21.

18. Chen LH, Hsieh MK, Liao JC, Lai PL, Niu CC, Fu TS, et al. Repeated 
percutaneous vertebroplasty for refracture of cemented vertebrae. Arch Orthop Trauma Surg 2011;131:927-33.

19. De S, Vazquez B. The effect of cross-linking agents on acrylic bone cements containing radiopacifiers. Biomaterials 2001;22:2177-81.

20. Bhambri SK, Gilbertson LN. Micromechanisms of fatigue crack initiation and propagation in bone cements. J Biomed Mater Res 1995;29:233-7.

21. Belkoff S, Molloy S. Temperature measurement during polymerization of polymethylmethacrylate cement used for vertebroplasty. Spine 2003;28:1555-9.

22. Baroud G, Samara M, Steffen T. Influence of mixing method on the cement temperature-mixing time history and doughing time of three acrylic cements for vertebroplasty. J Biomed Mater Res B Appl Biomater 2004;68:112-6.

23. Teng $\mathrm{M}$, Cheng $\mathrm{H}$, Ho $\mathrm{D}$, Chang $\mathrm{C}$. Intraspinal leakage of bone cement after vertebroplasty: A report of 3 cases. Am J Neuroradiol 2006;27:224-9.

24. Loeffel M, Ferguson SJ, Nolte L-P, Kowal JH. Vertebroplasty: Experimental characterization of polymethylmethacrylate bone cement spreading as a function of viscosity, bone porosity, and flow rate. Spine 2008;33:1352-9.

25. Lai PL, Tai CL, Chen LH, Nien NY. Cement leakage causes potential thermal injury in vertebroplasty. BMC Musculoskelet Disord 2011;12:116.

26. Jiranek W. Thermal manipulation of bone cement. Orthopedics 2005;28 (8 Suppl):s863-6.

27. Laidler KJ. The development of the Arrhenius equation. J Chem Educ 1984;61:494-500.

28. Chavali R, Resijek R, Knight S, Choi I. Extending polymerization time of polymethylmethacrylate cement in percutaneous vertebroplasty with ice bath cooling. Am J Neuroradiol 2003;24:545-6.

29. Smeds S, Goertzen D, Ivarsson I. Influence of temperature and vacuum mixing on bone cement properties. Clin Orthop Relat Res 1997;334:326-34.

30. James S, Connell D. The effect of temperature reduction on cement working time in percutaneous vertebroplasty. Clin Radiol 2006;61:797-9.

31. James SP, Jasty M, Davies J, Piehler H, Harris WH. A fractographic investigation of PMMA bone cement focusing on the relationship between porosity reduction and increased fatigue life. J Biomed Mater Res 1992;26:651-62.

32. Dean JR, Ison KT, Gishen P. The strengthening effect of percutaneous vertebroplasty. Clin Radiol 2000;55:471-6.

33. Luo J, Daines L, Charalambous A, Adams MA, Annesley-Williams DJ,
Dolan P. Vertebroplasty: Only small cement volumes are required to normalize stress distributions on the vertebral bodies. Spine 2009;34:2865-73.

34. Kurtz SM, Villarraga ML, Zhao K, Edidin AA. Static and fatigue mechanical behavior of bone cement with elevated barium sulfate content for treatment of vertebral compression fractures. Biomaterials $2005 ; 26: 3699-712$.

35. Theodorou DJ, Theodorou SJ, Duncan TD, Garfin SR, Wong WH Percutaneous balloon kyphoplasty for the correction of spinal deformity in painful vertebral body compression fractures. Clin Imaging 2002;26:1-5.

36. Bohner M, Gasser B, Baroud G, Heini P. Theoretical and experimental model to describe the injection of a polymethylmethacrylate cement into a porous structure. Biomaterials 2003;24:2721-30.

37. Turner TM, Urban RM, Singh K, Hall DJ, Renner SM, Lim TH, et al. Vertebroplasty comparing injectable calcium phosphate cement compared with polymethylmethacrylate in a unique canine vertebral body large defect model. Spine J 2008;8:482-7.

38. Lewis G, Towler MR, Boyd D, German MJ, Wren AW, Clarkin OM, et al. Evaluation of two novel aluminum-free, zinc-based glass polyalkenoate cements as alternatives to PMMA bone cement for use in vertebroplasty and balloon kyphoplasty. J Mater Sci Mater Med 2010;21:59-66.

39. Nieuwenhuijse MJ, Muijs SP, van Erkel AR, Dijkstra SP. A clinical comparative study on low versus medium viscosity polymethylmetacrylate bone cement in percutaneous vertebroplasty: Viscosity associated with cement leakage. Spine 2010;35:E1037-44.

40. Sabuncuoğlu H, Dinçer D, Güçlü B, Erdoğan E, Hatipoğlu HG, Ozdoğan S, et al. Intradural cement leakage: A rare complication of percutaneous vertebroplasty. Acta Neurochir (Wien) 2008;150:811-5.

41. Nussbaum DA, Gailloud P, Murphy K. A review of complications associated with vertebroplasty and kyphoplasty as reported to the Food and Drug Administration medical device related web site. J Vasc Interv Radiol 2004;15:1185-92.

42. Caynak B, Onan B, Sagbas E, Duran C, Akpinar B. Cardiac tamponade and pulmonary embolism as a complication of percutaneous vertebroplasty. Ann Thorac Surg 2009;87:299-301.

43. Krueger A, Bliemel C, Zettl R, Ruchholtz S. Management of pulmonary cement embolism after percutaneous vertebroplasty and kyphoplasty: A systematic review of the literature. Eur Spine J 2009; 18:1257-65.

44. Chen WJ, Kao YH, Yang SC, Yu SW, Tu YK, Chung KC. Impact of cement leakage into disks on the development of adjacent vertebral compression fractures. J Spinal Disord Techn 2010;23:35-9.

45. Lo YP, Chen WJ, Chen LH, Lai PL. New vertebral fracture after vertebroplasty. J Trauma 2008;65:1439-45. 